\title{
Playing with the senses: application of box-behnken design to optimize the bukayo formulation
}

\author{
*Domingo, C.J.A., De Vera, W.M., Pambid, R.C. and Austria, V.C. \\ Food Innovation Center, Pangasinan State University, Bayambang, Pangasinan, 2423, Philippines
}

\section{Article history:}

Received: 11 May 2019

Received in revised form: 5 July 2019

Accepted: 6 July 2019

Available Online: 13 July 2019

\section{Keywords:}

Bukayo,

Coconut,

Toffee,

Sinakob,

Response surface

methodology

\section{DOI:}

https://doi.org/10.26656/fr.2017.3(6).190

\begin{abstract}
A three-level Box-Behnken design of response surface methodology was employed to optimize the formulation of bukayo or coconut toffee based on overall acceptability sensory attribute. The independent variables were different levels of young coconut meat $(250-500 \mathrm{~g})$, sinakob $(250-500 \mathrm{~g})$, and coconut juice $(250-500 \mathrm{~g})$ with fifteen different runs of three similar center points. The analysis of variance showed that quadratically, coconut juice and sinakob showed significantly higher effect $(p<0.05)$ on the overall acceptability of bukayo whereas the "Lack of Fit" was non-significant relative to the pure error. For optimization, the goal was to maximize the overall acceptability response. The optimum formulation conditions of $430 \mathrm{~g}$ young coconut meat, $400 \mathrm{~g}$ sinakob, and $340 \mathrm{~g}$ coconut juice yielded an experimental overall acceptability score of 8.04 which is close to the predicted score of 7.11 with composite desirability of 0.87 on a nine-point hedonic scale. The regression model equation for overall acceptability could predict response yield until at least $84.65 \%$ of accuracy. Box-Behnken design of RSM performed well in the optimization of the bukayo formulation with a very high degree of overall acceptability. The strong and positive correlations enable the application of colorimetry as an indication of the overall acceptability and sensory color of the bukayo product.
\end{abstract}

\section{Introduction}

Coconut is one of the most important crops in tropical areas. Indonesia dominates the world as one of the biggest coconuts producing country with a production of 18 million tons of coconuts followed by the Philippines with an annual production of 15 million tons of coconuts (Burton, 2018). The various edible products from coconut include coconut milk, dried coconut or copra, desiccated coconut, coconut oil, coconut water, nata-de-coco, coconut flour, vinegar, and coconut jam (Sangamithra et al., 2013; Prades et al., 2016). Bukayo or coconut toffee is an after-meal sugar fix and one of the widely processed desserts in Pangasinan, Philippines. It is made by simmering coconut meat strips in a mixture of coconut juice and brown or white sugar until liquid is heavily reduced, the mixture is then formed into balls and left to harden to a chewy consistency (Pascual, 2017).

Experimental designs capable of predicting the optimum conditions of the combined factors are important to save time and resources. The most common approach is the classical one-variable-at-time technique. This method involves changing one variable at a time while keeping the others at constant levels (Keshani et al., 2010). While such experiments are simple to plan and execute, they are inefficient and failed to detect any interaction amongst the independent variables. Furthermore, it will require more experimentation and there is no assurance that it will produce reliable results (Montgomery, Runger and Hubbele, 2001). A BoxBehnken design was employed among other response surface methodologies because it provides the minimum number of experiments, a shorter time of operation, and feasibility of providing valuable information on the interactions among experimental parameters (Tan et al., 2012). Several researchers employed a Box-Behnken approach for optimization studies across the fields such as to optimize the drying process of persimmon leather production (Dursun and Dalgıç, 2018); to establish the optimum experimental condition of cake batter mixing (Tan et al., 2012); to optimize the foaming conditions for tomato juice as a function of egg albumin concentration, carboxymethyl cellulose, and whipping time (Balasubramanian et al., 2012), and to optimize spent hen meat level, oil level, and cooking time for development of ready-to-eat chicken meat caruncles on the basis of sensory attributes - color/appearance, flavor, 
crispiness, after-taste, meat flavor intensity, and overall acceptability (Singh et al., 2015).

In the realm of new product development, response surface methodologies hold the key position so that commercial production can be realized for a new product. With these response surface methodologies, the product developer can accomplish many different objectives ranging from understanding how ingredients and their interactions drive ratings, to optimizing a product subject to nonlinear constraints, and even reverse -engineering a formulation so that knowing the sensory or image profile can help determine what combination of formulation/process variables reproduce that subjective attribute profile (Moskowitz and Maier, 2007).

Effects of potassium sorbate on the shelf-life and sensory qualities of bukayo have been studied previously by Pascual (2017). Bukayo has not been studied before in terms of optimized production techniques. Hence, the objective of this study is to establish an optimal bukayo formulation by varying the amount of young coconut meat, sinakob, and coconut juice using a Box-Behnken design.

\section{Materials and methods}

\subsection{Materials preparation}

Young coconut meat (grated), coconut juice $\left(5.5^{\circ}\right.$ Brix), and sinakob (made from concentrated sugarcane juice) were purchased from the local market of Bayambang, Pangasinan. All materials except for sinakob came from the same batch. The preferred nut in processing bukayo is between 9 to 10 months old (PNS, 2017).

\subsection{Box-Behnken design}

Table 1. Variables and levels used in the Box-Behnken design.

\begin{tabular}{cccc}
\hline \multirow{2}{*}{ Variable } & \multicolumn{3}{c}{ Level } \\
\cline { 2 - 4 } & Low (-1) & Central (0) & High (+) \\
\hline Independent variables & & & \\
Young coconut meat & 250 & 375 & 500 \\
Sinakob (sugar) & 250 & 375 & 500 \\
Coconut Juice & 250 & 375 & 500 \\
Dependent variable & & & \\
Overall Acceptability & & & \\
\hline
\end{tabular}

A randomized Box-Behnken experimental design to establish the optimum experimental formulation of bukayo was implemented using Minitab Statistical Software Release 17 (Minitab Inc, State College, PA, USA). A Box-Behnken with three factors such as young coconut meat, sinakob, and coconut juice were selected to observe the effects on the overall acceptability of bukayo (Table 1). The coconut meat ranged from $250-$ $500 \mathrm{~g}$, sinakob from $250-500 \mathrm{~g}$, and coconut juice from $250-500 \mathrm{~g}$. A total of fifteen experimental runs with three factors and three levels were conducted. The order of the experiments was randomized to avoid any bias. A full quadratic polynomial model was chosen as the bestfitted model to demonstrate the influence of the factor and their interactions on the response variable (Tan et al., 2012; Liu et al., 2016).

\subsection{Bukayo preparation}

All the ingredients were weighed on a digital scale (NKS-6, Timbangan, Philippines). Ingredients were poured into a wok and cooked with stirring at medium fire for $30 \mathrm{~min}$. After cooking, the bukayo formulations were allowed to cool and stored for further analysis.

\subsection{Sensory analysis}

A nine-point hedonic test (1-dislike extremely, 2dislike very much, 3-dislike moderately, 4-dislike slightly, 5-neither like nor dislike, 6-like slightly, 7-like moderately, 8-like very much, and 9-like extremely) was performed to measure overall consumer acceptability, color, taste, sweetness, and texture of the fifteen (15) formulations of bukayo. A total of 50 untrained panelists whose ages range from 18 to 60 were randomly chosen from the University Campus. The panelists were told how to evaluate the samples using the parameters in the method explained by Everitt (2009).

\subsection{Validation of the optimized formulation}

The overall consumer acceptability of the optimized bukayo formulation was validated through a nine-point hedonic test. Experimental overall consumer acceptability was compared with the predicted overall consumer acceptability using a student t-test at $p=0.05$.

\subsection{Physical and chemical analyses of the preferred formulation}

Proximate analyses of the fifteen bukayo formulations were determined in terms of percent moisture content (925.49 B), crude fat (920.177), crude protein $(925.49 \mathrm{H})$, and water activity (978.18) using the methods used by the Association of Official Analytical Chemists (AOAC, 2016). Subtracting the sum of fat content, protein content, ash content, and moisture from 100 gave the total carbohydrate content (Onyeike et al., 2000). Lightness $\left(L^{*}\right)$, redness $(+a *)$, yellowness $\left(+b^{*}\right)$, hue angle $(\mathrm{h})$, and chroma $\left(\mathrm{C}^{*}\right)$ were measured against a High-Quality Portable Colorimeter (NR60CP, China).

\subsection{Statistical analyses}

The overall consumer acceptability response for the 
fifteen bukayo formulations was used with response surface methodology (RSM) to optimize Box-Behnken design factors. The numerical optimizations, contour plots, and the model equation were generated in Minitab Statistical Software Release 17 (Minitab Inc, State College, PA, USA) (Dursun and Dalgıç, 2018). Correlation heatmap was generated using the $\mathrm{R}$ (version 3.2.4, released 2016) statistical package.

\section{Results and discussion}

\subsection{Response surface regression analysis}

The analysis of variance is essential to test the significance and adequacy of the model. Fisher's $F$-test value was used to ascertain the goodness-of-fit of the regression model. As shown in Table 2, the $F$-value obtained, 3.06, is less than the $F$-value ( 250.84 at $95 \%$ significance) obtained from the standard distribution table, confirming the adequacy of the model. The significance of each factor was determined by $p$-value. Results revealed that the quadratic term of coconut juice and sinakob significantly influenced the overall acceptability of bukayo $(p<0.05)$. Meanwhile, the linear term of coconut juice, sinakob, and young coconut meat, the quadratic term of young coconut meat and the interaction effects were not significant $(p>0.05)$

The "Lack of Fit Test" compares the residual error to the pure error from replicated design points. The lack of fit $F$-value of 0.46 is not significant as the $p$-value is $>0.05$. The non-significance lack of fit suggested that the model was valid for the present study.

The resulting regression equation for the overall acceptability of bukayo was fitted as follows:

Overall Acceptability

$=-52.3+0.0380$ Young Coconut +0.1370 Sinakob

+0.1330 Coconut Juice -

0.000016 Young Coconut*Young Coconut -0.000160

Sinakob*Sinakob -

0.000128 Coconut Juice*Coconut Juice -

0.000016 Young Coconut*Sinakob -

0.000048 Young Coconut*Coconut Juice -

0.000032 Sinakob*Coconut Juice

Data from the Box-Benkhen was substituted into the model to evaluate the validation of the model through the coefficient of determination $\left(R^{2}\right)$, which represents the proportion that the model can explain for the variation in the responses. Models with $R^{2}$ values of $\geq 0.60$ can be considered as a valid model (Gong et al., 2007). The $R^{2}$ of the model was 0.85 which indicated a good fit between predicted values and the experimental data points. In addition, this implied that $84.65 \%$ of the variations for overall acceptability of bukayo are explained by the independent variables and this also suggested that the model does not explain only about $15.35 \%$ of the variation.

The overall acceptability was evaluated with four checkpoint batches. The results indicate that the measured sensory attributes were as expected. When measured sensory attributes were compared with predicted sensory attributes values using a student $t$-test, the differences were found to be insignificant $(p>0.05)$ indicating that the obtained mathematical equation is valid for predicting the overall acceptability of bukayo.

The relationship between the dependent and independent variables was further elucidated by constructing a contour plot. Three (3) 3D contour plots were generated from each response at the hold value of 375 (Figure 1). The contour plots of the overall acceptability of bukayo represented a response surface with a simple maximum, which suggests that the quality score increases as the color gets darker (Minitab, 2003). The darker regions identify higher z-values. The contour levels revealed a peak center in the vicinity of $350-500$ g young coconut meat (Figure 1a), $300-400 \mathrm{~g}$ sinakob (Figure 1b), and $350-450$ g coconut juice (Figure 1c). Overall acceptability scores in this peak region are greater than 7 .

\subsection{Response optimization}

After studying the effect of the independent variables on the response, the levels of these variables that give the desired response for the bukayo formulation was determined. The optimization and individual desirability of the response variable were obtained by specifying the goal. In this case, the goal chosen was to maximize the response. The target value for the response was set based on the definition of the best quality example, maximum overall acceptability score. In maximizing a response, the individual desirability is one for all response values greater than or equal to that target maximum and it increases for response values less than the target (Minitab, 2003). If the goal is to target response, the desirability is one at the target and decreases the more the response deviates from the target in either direction (Minitab, 2003).

The desirability approach is an established tool for the optimization of design variables including single and multiple responses (Varala et al., 2016). The response optimizer function of the Minitab software was used to find the optimum combination of bukayo formulation variables that maximizes the responses simultaneously using desirability function. A maximum level of overall acceptability was set for maximum desirability.

The behavior of the predicted responses was 
Table 2. Analysis of variance (ANOVA) for response surface quadratic model.

\begin{tabular}{clccccc}
\hline Source & DF & Adj SS & Adj MS & F-Value & P-Value \\
\hline \multirow{6}{*}{ Model } & 9 & 45.48 & 5.05 & 3.06 & 0.16 \\
& Linear & 3 & 6.75 & 2.25 & 1.36 & 0.36 \\
& Young Coconut & 1 & 0.5 & 0.5 & 0.3 & 0.61 \\
& Sinakob & 1 & 0.13 & 0.13 & 0.08 & 0.79 \\
& Coconut Juice & 1 & 6.13 & 6.13 & 3.71 & 0.11 \\
& Square & 3 & 35.23 & 11.74 & 7.12 & 0.03 \\
& Young Coconut*Young Coconut & 1 & 0.23 & 0.23 & 0.14 & 0.72 \\
& Sinakob*Sinakob & 1 & 23.08 & 23.08 & 13.99 & 0.01 \\
& Coconut Juice*Coconut Juice & 1 & 14.77 & 14.77 & 8.95 & 0.03 \\
& 2-Way Interaction & 3 & 3.5 & 1.17 & 0.71 & 0.59 \\
& Young Coconut*Sinakob & 1 & 0.25 & 0.25 & 0.15 & 0.71 \\
& Young Coconut*Coconut Juice & 1 & 2.25 & 2.25 & 1.36 & 0.3 \\
& Sinakob*Coconut Juice & 1 & 1 & 1 & 0.61 & 0.47 \\
Error & 5 & 8.25 & 1.65 & & \\
& & 3 & 6.25 & 2.08 & 2.08 & 0.34 \\
& Lack-of-Fit & 2 & 2 & 1 & & \\
& Pure Error & 14 & 53.73 & & & \\
\hline
\end{tabular}
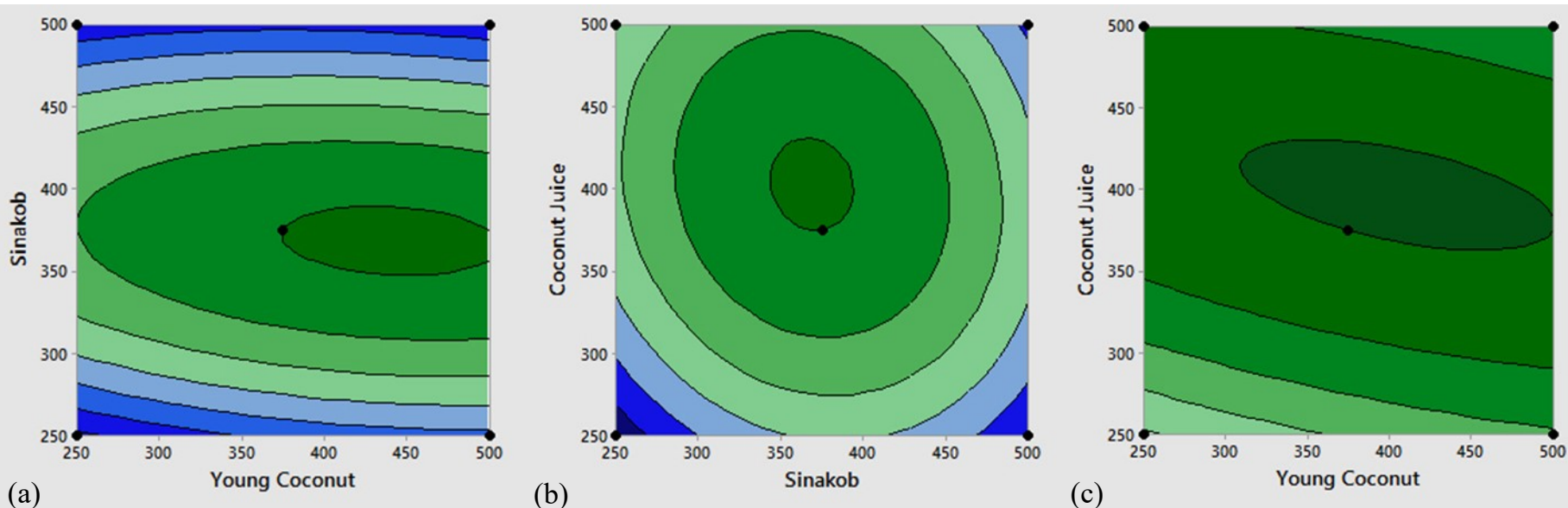

Figure 1. Effect of (a) young coconut meat and sinakob, (b) coconut juice and sinakob, (c) young coconut meat and coconut juice on the overall acceptability of bukayo.

generated from the optimized factors of $404.04 \mathrm{~g}$ young coconut meat, $368.69 \mathrm{~g}$ sinakob, and $398.81 \mathrm{~g}$ coconut juice, while the behavior of the actual responses which is predicted from a feasible experimental run at round figures of factor levels was also generated and compared. The goal for the response, the predicted response at current factor settings, $y$ and the individual desirability, $d$, are given in the left column. The vertical and horizontal lines on the graph represent the current factor settings and response values. The composite desirability of these observed optimum factors was 0.87 (Figure 2a).

In order to make these factors feasible in experimental runs, these observed optimum parameters were drawn to the nearest round figures of $400 \mathrm{~g}$ young coconut meat, $370 \mathrm{~g}$ sinakob, and $400 \mathrm{~g}$ coconut juice. From these rounded figures of factors, the individual desirability obtained for overall acceptability was retained at 0.87 (Figure $2 b$ ).

The optimized formulation was reproduced to validate the results and found out that the predicted overall acceptability (7.11) (Figure 2b) was found to be very close to the experimental overall acceptability
(8.04) on a nine-point hedonic scale. A mean liking score of 7.00 or higher on a nine-point scale is usually indicative of highly acceptable sensory quality (Everitt, 2009); hence, the optimized bukayo in this study could be used confidently as a good illustration of target quality.

\subsection{Comparison of the sensory and physicochemical characteristics of the bukayo formulation}

Listening to the voice of the consumers is important to realize the commercial production of a food product. In addition, this voice should be supported by instrumental analysis parameters. Correlations among physicochemical and sensory traits of bukayo were visualized through a heat map (Figure 3). Correlation coefficients were classified as weak $(\mathrm{r} \leq 0.35)$, moderate $(\mathrm{r}=0.36-0.67)$, and strong $(\mathrm{r}=0.68-1.00)$ (Taylor, 1990). All the sensory parameters were positive and strongly correlated. Water activity and crude protein were positive and moderately correlated with the overall acceptability; i.e. overall acceptability increased as water activity and crude protein increased. Interestingly, all the colorimeter values $\left(L^{*},+a^{*},+b^{*}, C, h\right)$ were positive 


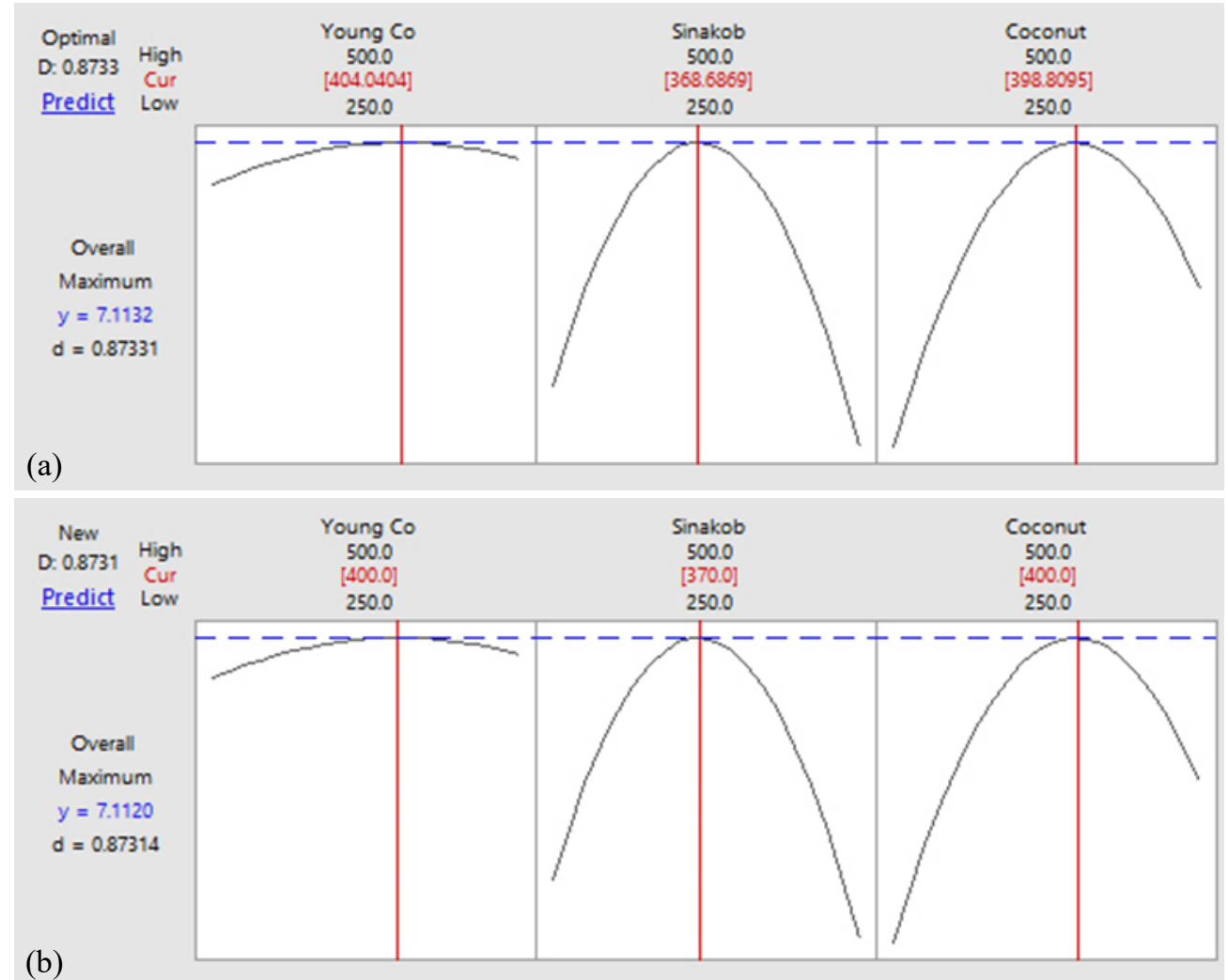

Figure 2. Response behavior of overall acceptability from (a) the observed optimum condition and (b) feasible experimental condition.

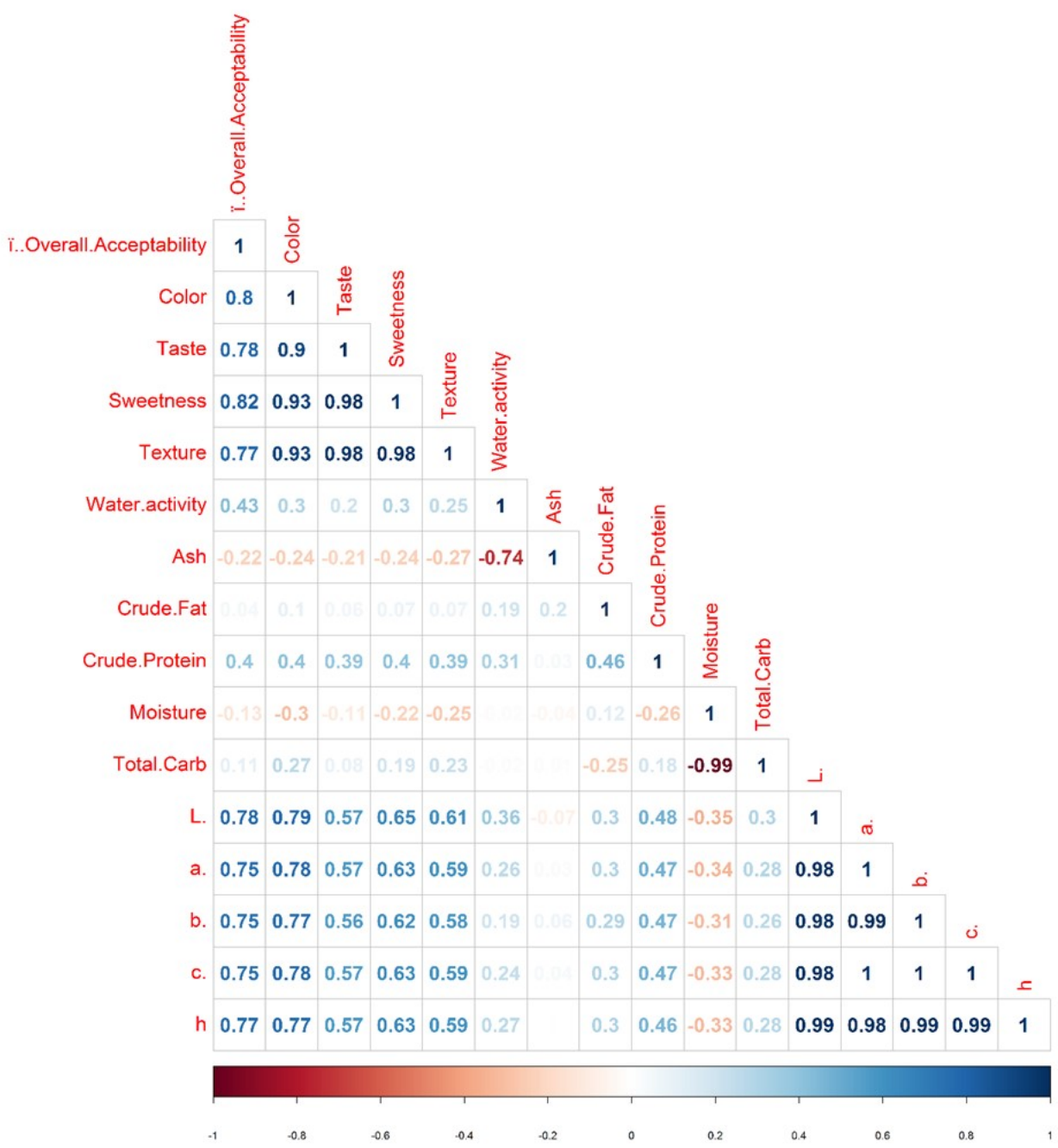

Figure 3. Heat map showing Pearson's correlation coefficients among the physicochemical and sensory characteristics of bukayo. 
and strongly correlated with overall acceptability. This indicates that colorimeter values have direct impacts on the quality of the final product and therefore, the quality of the bukayo could be regulated by controlling these properties.

\section{Conclusion}

A three-level Box-Behnken design was applied for modeling and optimizing of bukayo and three factors were defined as the variables: young coconut meat, sinakob, and coconut juice. Overall acceptability was defined as the response. Some conclusions have been drawn as follows: The $F$-values for the overall acceptability model was significant and that for "lack-offit" was non-significant $(p<0.05)$, thereby confirming the validity of the model. Also, this model adequately explained the variation of the response with satisfactory $R^{2}$ value, which indicated that $84.65 \%$ of the variations could be well explained by the model. By using the BoxBehnken design of the experiment, the optimal process formulations of bukayo were $400 \mathrm{~g}$ young coconut meat, $370 \mathrm{~g}$ sinakob, and $400 \mathrm{~g}$ coconut juice. This was selected to give a maximum overall acceptability score. Colorimeter values were positive and moderate to strongly correlated with the sensory parameters, hence, colorimetry can be used in the production of highly acceptable bukayo. This research can serve as a reference in terms of the optimization of native delicacies, investigating the effects of each process factor.

\section{Conflict of Interest}

All authors declare that there is no conflict of interest regarding the publication of this paper.

\section{Acknowledgments}

The authors acknowledge the support of Ricardo Velasco and Amy Penuliar during the conduct of the experiment. The cost of bukayo formulation optimization and analyses were covered through the funds available from the Philippine Council for Industry, Energy and Emerging Technology Research and Development (DOST-PCIEERD) Region 1 delicacies: development and standardization project.

\section{References}

AOAC. (2016). Official Methods of Analysis of the Association of the Official Analytical Chemists. 20th ed. Washington, DC, USA: AOAC.

Balasubramanian, S., Paridhi, G., Bosco, J. and Kadam, D. (2012). Optimization of Process Conditions for the Development of Tomato Foam by Box-Behnken
Design. Food and Nutrition Sciences, 3(7), 925-930. https://doi.org/10.4236/fns.2012.37122

Burton, J. (2018). The World Leaders In Coconut Production. Retreived from Worldatlas website: https://www.worldatlas.com/articles/the-worldleaders-in-coconut-production.html

Dursun, D. and Dalgıç, A. C. (2018). Production and preference mapping of persimmon fruit leather: An optimization study by Box-Behnken. Journal of Food Process Engineering, 41(8), e12899. https:// doi.org/10.1111/jfpe.12899

Everitt, M. (2009). Consumer-Targeted Sensory Quality. In Barbosa-Cánovas, G., Mortimer, A., Lineback, D., Spiess, W., Buckle, K. and Colonna, P. (Eds.), Global Issues in Food Science and Technology, p. 117-128. San Diego: Academic Press. https:// doi.org/10.1016/B978-0-12-374124-0.00008-9

Gong, W.J., Zhang, Y.P., Xu, G.R., Wei, X.J. and Lee, K.P. (2007). Optimization strategies for separation of sulfadiazines using Box-Behnken design by liquid chromatography and capillary electrophoresis. Journal of Central South University Technology, 14 (2), 196-201. https://doi.org/10.1007/s11771-0070039-7

Keshani, S., Luqman Chuah, A., Nourouzi, M.M., Russly, A.R. and Jamilah, B. (2010). Optimization of concentration process on pomelo fruit juice using response surface methodology (RSM). International Food Research Journal, 17, 733-742.

Liu, H., Shi, A., Liu, L., Wu, H., Ma, T., He, X., Lin, W., Feng, X. and Liu, Y. (2016). Peanut Protein Processing Technology. In Wang, Q. (Ed.) Peanuts: Processing Technology and Product Development, $\mathrm{p}$. 83-209. USA: Academic Press. https:// doi.org/10.1016/B978-0-12-809595-9.00004-1

Minitab. (2003). Minitab statistical software, release 14 for windows. Pennsylvania, USA: State College.

Montgomery, D.C., Runger, G.C. and Hubbele, N.F. (2001). Engineering Statistics. New York: John Wiley and Sons, Inc.

Moskowitz, H.R. and Maier, A. (2007). Response surface methodology and consumer-driven product optimization. In Beckley, J.H., Foley, M., Topp, E.J., Huang, J.C. and Prinyawiwatkul, W. (Eds.). Accelerating New Food Product Design and Development, p. 297-349. USA: Blackwell Publishing and the Institute of Food Technologists. https://doi.org/10.1002/9780470277621.ch17

Onyeike, E.N., Ayalogu, E.O. and Ibegbulem, C.O. (2000). Evaluation of the nutritional value of some crude oil polluted freshwater fishes. Global Journal of Pure and Applied Sciences, 6(2), 227-233. https:// doi.org/10.4314/gjpas.v6i2.16112 
Pascual, P.A.L. (2017). Determining the effects of potassium sorbate on the shelf-life and sensory qualities of bukayo Asian Journal of Multidisciplinary Studies, 5(4), 167-171.

PNS (The Philippine National Standard). (2017). Code of Good Agricultural Practices (GAP) for Coconut. Phillipines: PNS.

Prades, A., Salum, U.N. and Pioch, D. (2016). New era for the coconut sector. What prospects for research? Oilseeds and Fats Crops and Lipids, 23(6), 1-4. https://doi.org/10.1051/ocl/2016048

Sangamithra, A., Swamy, G.J., Sorna, P.R., Chandrasekar, V., Sasikala, S. and Hasker, E. (2013). Coconut: An extensive review on valueadded products. Indian Food Industry Mag, 32(6), 29-36.

Singh, P., Sahoo, J., Talwar, G., Chatli, M.K. and Biswas, A.K. (2015). Development of chicken meat caruncles on the basis of sensory attributes: process optimization using response surface methodology. Journal of Food Science and Technology, 52(3), 1290-1303. https://doi.org/10.1007/s13197-013-1160 $-2$

Tan, M.C., Chin, N.L. and Yusof, Y.A. (2012). A BoxBehnken Design for Determining the Optimum Experimental Condition of Cake Batter Mixing. Food and Bioprocess Technology, 5(3), 972-982. https://doi.org/10.1007/s11947-010-0394-5

Taylor, R. (1990). Interpretation of the correlation coefficient: A basic review. Journal of Diagnostic Medical Sonography, 6, 35-39. https:// doi.org/10.1177/875647939000600106

Varala, S., Dharanija, B., Satyavathi, B., Basava Rao, V.V. and Parthasarathy, R. (2016). New biosorbent based on deoiled karanja seed cake in biosorption studies of $\mathrm{Zr}(\mathrm{IV})$ : Optimization using Box-Behnken method in response surface methodology with desirability approach. Chemical Engineering Journal, 302, 786-800. https://doi.org/10.1016/ j.cej.2016.05.088 